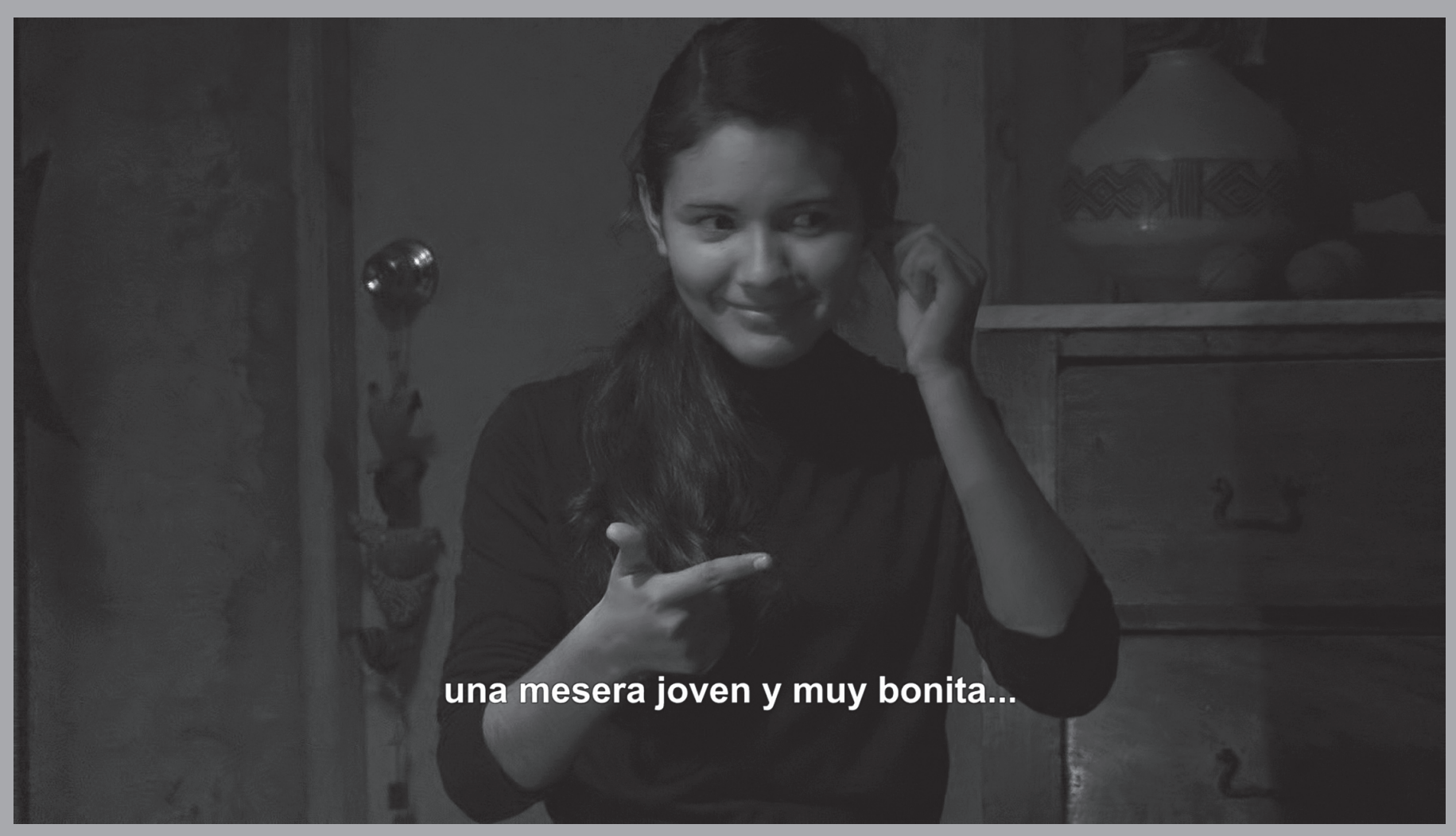

Fotograma del audiovisual Campo. 


\title{
Campo
}

\section{El primer cortometraje nacional en lengua de señas}

\author{
Por Betina Gersberg
}

\section{El concurso}

La Organización de Estados Iberoamericanos ${ }^{1}$ convocó, a fines de 2011, a un concurso de cine y escritura ${ }^{2}$ para que escuelas y liceos de toda Iberoamérica escribieran guiones de ficción para cortometraje. Se presentaron dos en lengua de señas. Si bien el concurso era para lenguas oficiales y la lengua de señas lo es, no estaba contemplada. El jurado decidió apoyar la iniciativa y contactó a la Universidad Católica del Uruguay (UCU) para producir uno de esos dos cortos. Se trató del guión desarrollado por alumnos de la Escuela n. ${ }^{0} 116$ bilingüe para sordos de la ciudad de Salto, al norte del país.

\section{Un producto nativo}

"Cuando asumimos el compromiso de producir el guión había dos cosas importantes para definir, que delimitan el producto tal cual es hoy", explicó Natalia Espasandín, directora del cortometraje e integrante del Departamento de Comunicación de la Facultad de Ciencias Humanas de la UCU. "Una era si el corto se iba a contar en lengua de señas o si iba a tener una traducción al español y lo interpretarían actores hablando. Es decir, que hubiese sido creada la historia en lengua de señas no implicaba que necesariamente se produjera en ese idioma, pero para la Universidad ese era el reto más interesante. Una vez que ese punto se resolvió, el equipo de Salto puso también una condición: el elenco tenía que estar conformado por actores sordos". Así se dio lugar a la creación de Campo, el primer cortometraje de ficción nacional enteramente en lengua de señas uruguaya. "Todos los actores tienen distintos niveles de sordera y saben señar".

\section{Una metodología bilingüe}

El otro aspecto definitorio sobre el cortometraje fue la metodología de producción. "Al principio nos dijeron 'ustedes háganlo como un servicio de producción', es decir, nos dan el guión, nosotros producimos y lo devolvemos al cliente, quien dirá si le gusta o no. Pero luego de juntarnos con los chicos y ver sus ganas de participar, nos pareció que la única forma en la que podríamos producir Campo era en conjunto. Trabajar como servicio de producción tiene el riesgo de que la historia carezca de corazón, aunque asegura la calidad técnica. Por otra parte, las producciones participativas aseguran el corazón, pero arriesgan la calidad
Ficha técnica Título:: Campo Ciudad, Año:: Salto, 2012 Duración:: 9 minutos Dirección:: Natalia Espasandin 
Campo se realizó en el marco del Programa Iberoamericano de las Lenguas en la Educación en conjunto con el Ministerio de Educación y Cultura y la Administración Nacional de Educación Pública de Uruguay,y contó con el apoyo de varias instituciones locales $\mathrm{e}$ internacionales.

Un guión literario audiovisual de ficción es un formato de escritura técnico-literaria que, en general, implica el desarrollo de un argumento en escenas, con descripciones de tiempo y espacio, personajes, acciones y diálogos, o detalles importantes de la realización audiovisual, en el orden en el que se espera que el espectador los reciba una vez producido el audiovisual

(Espasandin, en entrevista).

El equipo profesional que apoyó en la creación del guión,

su traducción al español y su

delimitación teórica estuvo integrado por César Cooper, Elsa García, Mariana Silveira (por la Escuela n. 116 biblingüe para sordos de la ciudad de Salto) y Leonardo Peluso (por la tecnicatura universitaria en Interpretación LSU-EspañolLSU, Facultad de Humanidades y Facultad de Psicología, Regional Norte, Universidad de la República).

Scouting es la acción de buscar y seleccionar locaciones para una filmación.

arias instituciones $p$ producción de Campo, que se desarrolló en el marco del Programa lberoamericano de las Lenguas en la Educación, en conjunto con el Ministerio de Educación y Cultura y la Administración de Educación Pública de Uruguay, entre otras instituciones nacionales e internacionales, entre ellas la Universidad de la República. profesional del producto”. Finalmente, se acordó trabajar con un sistema mixto, en el que egresados y estudiantes avanzados de las carreras de Comunicación Social e Ingeniería Audiovisual de la UCU fueron cabeza de equipo, y en otros roles (de guión, traducción, producción y asistencia) se incluyeron integrantes de la comunidad sorda. "El acuerdo en estos sistemas mixtos es que cada uno aporta lo que sabe para lograr un fin común. En Campo $^{3}$ generamos una dinámica que no es fácil, porque tiene muchas exigencias, pero permitió un buen producto".

\section{Hacia un guión audiovisual}

La Escuela n. ${ }^{\circ} 116$ presentó para el concurso un video y un guión escrito. "Yesica Nuñez, la alumna que inventó la historia, junto a sus compañeros, se filmó señando la historia, porque esta es la forma más parecida a la escritura que tiene la lengua de señas; la uruguaya, al igual que muchas otras lenguas de señas, no tiene su versión escrita”. Espasandín explicó que el guión presentado necesitaba ser ajustado a un formato profesional audiovisual. ${ }^{4}$ Para ello, el equipo profesional tomó el material presentado y comenzó el trabajo de adaptación. "Lo primero que hicimos fue simplemente una transposición: ${ }^{5}$ pasamos lo que estaba escrito al formato de guión paginado, donde está definida la forma en que se pasa de una escena a otra, que tiene una estructuración para los diálogos, una para las descripciones, otra para el paso del tiempo...”.

Esa primera etapa de traducción mostró que había que ajustar la historia porque, por un lado, se planteaban acciones inviables de filmar [para el alcance del proyecto] y, por otro, había que trabajar especialmente los puntos de inflexión de la historia. "La narración occidental tradicional vive y se nutre de conflictos, y si no hay conflictos reales le falta alguna polea dramática a la narración. La historia original tenía algunas diferencias en este sentido. Aunque, de a poco, nos fuimos dando cuenta de que en la cultura de sordos tenía sentido".

El equipo de la Universidad generó propuestas para resolver los puntos débiles de la historia con el propósito de que, sin cambiar el espíritu original, se volviera "un producto integrado que funcionara para ambos públicos, oyentes y sordos. Ese fue el desafío”.

En la reescritura del guión, trabajó un equipo de quince alumnos y egresados, que se reunió dos veces en Salto para leer-traducir cada escena del video y ajustar el guión escrito. "Fuimos viendo bloque por bloque lo que nosotros les proponíamos, discutiéndolo, cambiándole cosas y grabando con una camarita de fotos cada fragmento. Así logramos saber cómo se expresaba cada parte del texto en lengua de señas uruguaya y cuáles eran las informaciones mínimas que en cada parte del relato debían cumplirse para que funcionara la historia. Esa fue nuestra guía para el rodaje y para la edición".

\section{Particularidades de un idioma}

Esta experiencia de producción generó en el equipo profesional un aprendizaje adicional: "Las comunidades que tienen una diferencia sensorial son muy autosuficientes en muchos otros sentidos. Forman un colectivo, se reúnen, tienen sus códigos, sus formas de expresarse, una lengua propia... todo eso genera una cultura propia. En la lengua de señas no se traducen literalmente las frases. Si bien hay un deletreo, las expresiones tienen una seña que las resume. Por ejemplo, para decir 'Hoy está lindo' hay un gesto, una seña que lo dice (no se dice una a una cada palabra). Como la forma en que se estructura la lengua es distinta, entonces el pensamiento que se genera es diferente también. Lo que he logrado entender de la cultura de sordos es que se expresan de 
forma mucho más directa en las ideas, las emociones, los sentimientos, y las historias reflejan eso", compartió Espasandín.

\section{Un rodaje exigido}

El pueblo de Belén, del departamento de Salto, fue la locación definida para el rodaje. La filmación en el norte del país implicó varios viajes de preproducción para trabajar el guión, el scouting, ${ }^{6}$ hacer el casting y reunirse con los actores. Durante este proceso algunos técnicos se fueron familiarizando con el nuevo idioma. "Si bien había intérpretes quisimos comunicarnos con los actores directamente. No aprendimos 100\% ni mucho menos, pero chapoteamos... Hicimos mucho hincapié en aprender y enseñar las palabras clave del vocabulario de lo que iba a pasar durante el rodaje. Por ejemplo, aprendí que 'campo' se decía de tal manera [hace la seña]. Y bueno, así fuimos trabajando".

Además de la convivencia de los dos idiomas, la filmación fue un desafío importante por la fecha límite de entrega del producto final: el cortometraje se iba a presentar la primera semana de setiembre en el Congreso Iberoamericano de Lenguas en Salamanca y los cortos tenían que estar prontos un mes antes.

Desde que comenzó la preproducción hasta que el producto estuvo terminado, pasaron dos meses, y se cumplió así con las fechas previstas.

El rodaje llevó una larga jornada en Salto en la que no faltaron obstáculos: "Las mayores dificultades fueron el idioma y la carencia de recursos. Hubo muchas cosas que las hicimos a pulmón y que se consiguieron por el gran compromiso de muchos ${ }^{7}$ para que el producto saliera en tiempo y forma. También hubo aporte económico que, obviamente, ayudó. Si bien hubo momentos difíciles, como en toda producción, fue una aventura agotadora, pero tremenda aventura”, concluyó Espasandín.

\section{El aporte universitario}

"Un altísimo porcentaje (en Uruguay ni que hablar) de producciones en lengua de señas se remiten a filmaciones de alguien que está señando. Y esta lengua no se reduce solamente a la mano, es el movimiento de la mano en relación con el cuerpo, en el lugar del cuerpo, la posición... se maneja todo el espacio aéreo. En lenguaje audiovisual eso se traduce a un plano medio, entreabierto, siempre despejado. Antes del rodaje vimos muchos audiovisuales en lengua de señas en los que hay mucha frontalidad, y esto hace que no se vean como una historia sino como un registro", explicó Espasandín. "Nosotros queríamos que Campo se viera y sintiera como una película que ves en otro idioma y no por eso la dejás de entender. No inventamos la pólvora, pero aplicamos un código, el audiovisual, a algo que no se estaba aplicando de esa manera. Y generamos un producto que es resultado de un proceso mixto y que funciona como producto integrado".

Para producir audiovisuales en cualquier nivel cinematográfico -televisivo, web, lo que fuera- se requiere de fondos. "El mercado no financiaría para una comunidad que es minoría a nivel global una producción sistematizada. En cambio, una universidad puede generar este tipo de proyectos que en el mercado no se da. Es posible producir con una cabeza de accesibilidad, es un tipo de extensión en investigación”, respondió Espasandín sobre qué puede ofrecer el ámbito universitario para potenciar la participación de la comunidad sorda en lo audiovisual. "Se pueden hacer producciones interesantes con la misma calidad que cualquier producción en otro idioma. Me gusta pensar que Campo es un granito de arena para ver que esto es posible".:
Betina Gersberg:: (Montevideo, 1980) es egresada de la Licenciatura en Comunicación Social de la Universidad Católica de Uruguay. Integra el equipo de la Secretaría de Comunicación Institucional de la misma universidad. Se dedica a la comunicación organizacional y audiovisual de manera independiente. Forma parte del equipo de la revista dixit desde su creación, en 2006.

bgersberg@ucu.edu.uy 